\title{
Intergenerational Educational Mobility in Denmark and the United States
}

\author{
Stefan B. Andrade, Jens-Peter Thomsen
}

The Danish Center for Social Science Research

Abstract: An overall finding in comparative mobility studies is that intergenerational mobility is greater in Scandinavia than in liberal welfare-state countries like the United States and United Kingdom. However, in a recent study, Landersø and Heckman ( $L$ \& H) (2017) argue that intergenerational educational mobility in Denmark and the United States is remarkably similar. $L$ \& H's findings run contrary to widespread beliefs and have been echoed in academia and mass media on both sides of the Atlantic Ocean. In this article, we reanalyze educational mobility in Denmark and the United States using the same data sources as $L \& H$. We apply several different methodological approaches from economics and sociology, and we consistently find that educational mobility is higher in Denmark than in the United States.

Keywords: education and inequality; comparative analyses of education systems; intergenerational educational mobility

Citation: Andrade, Stefan B., and Jens-Peter Thomsen. 2018. “Intergenerational Educational Mobility in Denmark and the United States." Sociological Science 5: 93-113.

Received: December 7, 2017

Accepted: January 9, 2018

Published: February 14, 2018

Editor(s): Jesper Sørensen, Stephen Morgan

DOI: $10.15195 /$ v5.a5

Copyright: (C) 2018 The Author(s). This open-access article has been published under a Creative Commons Attribution License, which allows unrestricted use, distribution and reproduction, in any form, as long as the original author and source have been credited. (0)(1)
TEQUALITY of educational opportunity is a major concern for all welfare states, 1 and since the 1960s, governments have spent a considerable share of their gross domestic product on education to enhance economic growth and educational opportunities. Educational mobility - the degree to which children's education is unrelated to parental social background-is widely viewed as a marker of how well governments are able to mobilize resources to meet rising demands and support citizens in fulfilling their educational potential, regardless of social origin (Organisation for Economic Cooperation and Development 2017). For this reason, comparing educational mobility is central for the study of inequality of educational opportunity, not least because disparities in mobility rates across countries may propel policy recommendations with wide-ranging consequences for the functioning of the welfare state.

Social scientists have developed various approaches for comparing intergenerational mobility rates, with sociologists mainly focusing on social and educational mobility and economists looking at income mobility (Breen and Jonsson 2005; Black and Devereaux 2011; Torche 2016). An overall finding within comparative mobility studies is that intergenerational mobility is greater in Scandinavia than in liberal welfare-state countries like the United States and United Kingdom (Bjørklund et al. 2002; Esping-Andersen 2005; Jäntti et al. 2006; Hertz et al. 2008; Blanden 2013; Corak 2013). The Great Gatsby curve (Corak 2013)—which shows correlations between intergenerational earnings elasticity and income inequality-and Wilkinson and Picketts' (2009) book The Spirit Level—which compares the associations between inequality and health and social problems in western countries-are two prominent, popularized examples of these findings. 
However, in a recent study, Landersø and Heckman (L \& H) (2017) argue that educational mobility in Denmark and the United States is remarkably similar. L \& $\mathrm{H}$ explain their findings through references to institutional differences between the two countries. The Danish welfare state-having progressive taxation, high levels of social benefits, and free education-provides low levels of labor market incentives. The generous social benefits and little difference in income between people with lower and higher levels of education mean that the Danish welfare state dampens incentives for pursuing higher education, thereby reducing educational mobility in Denmark (Landersø and Heckman 2017:220). L \& H conclude that the true educational potential of young Danes would stand a better chance of being realized if there were stronger financial incentives for young people to pursue higher education-citing wage compression and higher levels of welfare benefits in Denmark as counterproductive in providing incentives to pursue educationand that the "low returns to education observed in Denmark help to explain the disconnect between the egalitarian childhood policies in Denmark and the roughly equal levels of educational mobility in Denmark and the US" (p. 219-20).

L \& H's findings of "remarkably similar" (p. 198) levels of intergenerational educational mobility in Denmark and the United States run contrary to widespread beliefs and have been disseminated in academic communities and mass media on both sides of the Atlantic Ocean (Thompson 2016; Landersø 2016; O'Brien 2016; Baumann 2017). For Danish researchers and politicians, the findings have elicited both surprise and concern. If educational mobility in Denmark is not higher than that of the United States, this leaves the Danish welfare state in a major legitimation crisis. With progressive taxation, high levels of social benefits, heavily subsidized and nearly universal high standards of day care, a tuition fee-free higher education system, and generous government grants for students older than 18, the Danish welfare state should be providing better educational opportunities for its citizens than the United States.

The validity of the conclusions reached by $\mathrm{L} \& \mathrm{H}$ rests on the statement that educational mobility in Denmark and the United States is, in fact, similar. If this statement turns out to be unsubstantiated or disputable, it concomitantly undermines the authors' conclusions and policy recommendations. In this article, we reanalyze educational mobility in Denmark and the United States using the same data sources used by L \& $\mathrm{H}$ as laid out in section III of their article, in which L \& H arrive at the conclusion that educational transitions across generations are similar in Denmark and the United States (p. 198-99). ${ }^{1}$ We apply several different methodological approaches from economics and sociology, and we consistently find that educational mobility is higher in Denmark than in the United States. Consequently, we dispute L \& H's statement.

The article proceeds as follows. We begin by detailing how $\mathrm{L} \& \mathrm{H}$ arrive at their conclusion (2017:198-99). We thereafter outline our strategy for reanalyzing the data, examine qualitative differences in both countries' education systems, and describe the data and methods used, followed by a presentation of our results. We end the article by discussing the implications of our findings. 
Table 1: Participation of 20- to 34-year-olds in tertiary education by parents' education in Denmark and the United States.

Denmark United States

\begin{tabular}{lcc}
\hline A. Distribution of origin (parents' education) within tertiary education (column percentages) & \\
Parents' education: & 7 & 8 \\
Below upper secondary education & 30 & $34^{\mathrm{a}}$ \\
Upper secondary or postsecondary, nontertiary education & 63 & 58 \\
Tertiary education & 100 & 100 \\
Total & Reference & Reference \\
\hline B. Chances of participating in tertiary education by parents' education (relative risk) & 1.6 & 2.9 \\
Parents' education: & 3.0 & 6.8 \\
Below upper secondary education & \\
Upper secondary or postsecondary, nontertiary education & \\
Tertiary education &
\end{tabular}

Notes: Data are from the OECD (2014:92-93, Tables A4.1a and A4.1b). ${ }^{\text {a }}$ There is a misprint in Landersø and Heckman's (2017) Figure 6 stating that 37 percent have an upper secondary or postsecondary, nontertiary education origin. We report the correct percentages from the OECD here.

\section{Landersø and Heckman's Statement}

L \& H base their statement that educational mobility in Denmark and the United States is "remarkably similar" on three sources: (1) Organisation for Economic Cooperation and Development (OECD) data, (2) a comparative analysis by Hertz et al. (2008), and (3) the authors' own tables on educational parent-child transitions in Denmark and the United States (p. 198-99). In this section, we examine the extent to which each of these sources supports statements on similar educational mobility patterns in Denmark and the United States.

\section{OECD Data}

L \& H point to data from the OECD report Education at a Glance 2014: OECD Indicators (2014:92, Table A4.1a) as a source of support for a statement of similar educational mobility in Denmark and the United States. The figures are reproduced on page 200 in L \& H's article and are provided in panel A of Table 1 in this article.

Panel A in Table 1 shows the fraction of young people ages 20 to 34 in tertiary education by their parents' educational attainment in Denmark and the United States. From the distribution in panel A, L \& H observe that there are "few differences" in percentages across countries (p. 198). However, we argue that the figures in panel A alone cannot support drawing conclusions about the similarity in educational mobility between the two countries. The problem is that these figures are an example of selection on the dependent variable: they only report the distribution of social origin within one destination category (students in tertiary education). The seemingly similar percentages in panel A could, in principle, cover up very different origin and destination associations for each social origin. For example, it 
could be the case that children of parents with no secondary education had a 10 percent chance of attaining tertiary education in the United States and a 20 percent chance in Denmark. However, as we are not presented with the origin distribution, we cannot know whether this is the case. ${ }^{2}$

To assess the magnitude of family background influence on children's educational attainment, the first step is to investigate the distribution of educational destinations within each social origin category. The OECD (2014) provides this data and uses it to calculate how likely children in one social group are to achieve tertiary education relative to children in another social group (OECD [2014:93, Table A4.1b] and panel B in Table 1 in this article). The result is a relative risk measure (which the OECD somewhat misleadingly calls "odds ratios"). As relative risk (and odds ratio) measures compare the likelihoods of an event happening in two different groups, they account for marginal distributions by taking into account the distribution of destinations within each social group. By calculating this measure, the OECD reaches a different conclusion than L \& H: In the United States, the chances of children obtaining tertiary education when their parents have tertiary education are 6.8 times greater than they are for children of parents with no secondary education. In Denmark, educational mobility is considerably higher, where children of tertiary-educated parents only have 3.0 times the chance of obtaining tertiary education relative to children of parents with no secondary education. In short, we argue that L \& H reproduce OECD figures with obvious shortcomings when a superior alternative is readily available from the same source.

\section{Hertz et al. (2008)}

In addition to the OECD figures, $\mathrm{L} \& \mathrm{H}$ base their argument on a comparative study by Hertz et al. (2008) about long-run trends in educational inequality. Hertz and his colleagues use linear regression models to estimate the importance of family background on educational attainment for citizens ages 20 to 69 from 42 nations across 50 years, and they do, in fact, find rather similar coefficient sizes for the United States and Denmark (0.49 for Denmark vs. 0.46 for the United States). However, for the same data, Hertz et al. (2008:25, Table 7) also report correlations between children's and parents' education and find that correlations are considerably lower for Denmark (as well as for the other Nordic countries) than for the United States ( 0.30 for Denmark vs. 0.46 for the United States).

Although Hertz et al. (2008) argue that the two measures of educational mobility have different pros and cons, they conclude that "in addition to being more stable over time, the correlations are less sensitive to small differences in the ways samples and variables are defined, which is a point in their favor" (p. 17). Because the correlations are less volatile than the regression coefficients, Hertz and his colleagues mainly focus on this measure in assessing the magnitude of educational mobility in different countries (p. 14). Whereas the beta coefficients show the United States (0.46) to be one of the most mobile countries-much lower than, for example, Sweden (0.58) - the United States is among the least mobile countries by correlation (0.46), with Nordic countries being among the most mobile ( 0.34 on average) ( $p$. $25)$. These differences are in line with other social mobility studies showing that 
the Nordic countries are more mobile than the United States (Breen and Jonsson 2005; Esping-Andersen 2005; Jäntti et al. 2006; Blanden 2013). Thus, Hertz et al. conclude that "one important general finding in the income-mobility literature is reproduced in the education data, namely that the Nordic countries have low rates of intergenerational status persistence" (p. 25).

Nevertheless, L \& H choose to focus on the beta coefficients of Hertz et al. (2008) without reporting the correlations. We believe it is fair to say that Hertz et al. show mixed results when it comes to educational mobility. By correlations, the measure preferred by Hertz et al., educational mobility in Denmark is substantially higher than that of the United States; by beta coefficients, Denmark and the United States are roughly equal.

\section{L \& H's Own Calculations}

L \& H supplement their reading of OECD (2014) and Hertz et al. (2008) with their own data, reproduced in Figure A30 in their article's Online Appendix. In this figure, the authors investigate father-child educational transitions using three levels: no high school, at least high school, and college. L \& H compare birth cohorts from 1955 to 1985 for the two countries and conclude that "[e]ducational transitions across generations are very similar in the two countries for more recent cohorts" (p. 199).

We have reanalyzed data using the same sources as in Figure A30. ${ }^{3}$ We observe that L \& H make several methodological choices that may bias the analysis: (1) measuring family origin by fathers' education only (omitting households for which information on fathers' education is missing), (2) coding educational levels from years of education when direct information on educational levels achieved (diplomas and/or degrees attained) is readily available in both Danish and U.S. data, and (3) using children's educational status at age 27, thereby possibly underreporting the educational level in Denmark (the median university and university college graduating age was 28 in Denmark in 2007).

In our reanalysis, we use the same data sources and variables but focus on the educational status in 2013 of 29- to 33-year-olds (born 1980-1984) in Denmark and the United States given their parents' highest level of education. We present our findings in Table 2. ${ }^{4}$ We report children's educational attainment by their parents' education using both the father's highest education (as reported in L \& H's Figure A30) and the highest education of both the mother and father. We consider the latter to be a more appropriate measure given the rising educational levels of mothers (Beller 2009) and that many (largely single-mother) households in Denmark and the United States would be omitted if we only include children for whom we have information on the father's education.

Table 2 reports children's highest educational attainment using years of education and the highest degree attained. Because data for the two countries rely on different sources—administrative data (Denmark) and survey data (the National Longitudinal Survey of Youth for the United States)-years of education are not measured in the same way. Whereas the U.S. data measure years of education as the highest grade completed, years of education in Denmark are measured as the 
Table 2: Children's educational status (2013) by parents' education (shown as column percentages) for the 1980-1984 cohorts.

\begin{tabular}{|c|c|c|c|c|c|c|}
\hline \multirow[b]{4}{*}{ Child's years of education } & \multicolumn{6}{|c|}{ Continuous measures } \\
\hline & \multicolumn{6}{|c|}{ Father's years of education } \\
\hline & \multicolumn{3}{|c|}{ Denmark $(N=235,757)$} & \multicolumn{3}{|c|}{ United States $(N=4,367)$} \\
\hline & $0-11.9$ & $12-14.9$ & $15+$ & $0-11.9$ & $12-14.9$ & $15+$ \\
\hline $0-11.9$ & 30 & 16 & 7 & $32(32)$ & $13(13)$ & $5(5)$ \\
\hline $12-14.9$ & 46 & 46 & 27 & $50(49)$ & $48(47)$ & $22(22)$ \\
\hline 15 or more & 24 & 37 & 66 & $19(19)$ & $39(40)$ & $73(73)$ \\
\hline \multirow[t]{3}{*}{ Total } & 100 & 100 & 100 & 100 & 100 & 100 \\
\hline & \multicolumn{6}{|c|}{ Parents' years of education } \\
\hline & \multicolumn{3}{|c|}{ Denmark $(N=250,954)$} & \multicolumn{3}{|c|}{ United States $(N=4,983)$} \\
\hline Child's years of education & $0-11.9$ & $12-14.9$ & $15+$ & $0-11.9$ & $12-14.9$ & $15+$ \\
\hline $0-11.9$ & 37 & 18 & 8 & $43(45)$ & 17 (17) & $6(6)$ \\
\hline $12-14.9$ & 45 & 49 & 29 & $45(43)$ & $50(50)$ & $26(26)$ \\
\hline 15 or more & 18 & 33 & 63 & $13(13)$ & $33(34)$ & $68(69)$ \\
\hline \multirow[t]{4}{*}{ Total } & 100 & 100 & 100 & 100 & 100 & 100 \\
\hline & \multicolumn{6}{|c|}{ Categorical measures } \\
\hline & \multicolumn{6}{|c|}{ Father's highest degree } \\
\hline & \multicolumn{3}{|c|}{ Denmark $(N=235,757)$} & \multicolumn{3}{|c|}{ United States $(N=2,755)$} \\
\hline Child's highest degree & No HS & HS & College & No HS & HS & College \\
\hline No HS & 25 & 14 & 7 & $26(26)$ & $11(11)$ & $4(4)$ \\
\hline HS & 47 & 45 & 24 & $50(48)$ & $48(46)$ & $25(24)$ \\
\hline College & 27 & 41 & 69 & $25(27)$ & $41(43)$ & $72(73)$ \\
\hline \multirow[t]{3}{*}{ Total } & 100 & 100 & 100 & 100 & 100 & 100 \\
\hline & \multicolumn{6}{|c|}{ Parents' highest degree } \\
\hline & \multicolumn{3}{|c|}{ Denmark $(N=250,954)$} & \multicolumn{3}{|c|}{ United States $(N=4,474)$} \\
\hline Child's highest degree & No HS & HS & College & No HS & HS & College \\
\hline No HS & 32 & 16 & 8 & $38(39)$ & $18(17)$ & $6(6)$ \\
\hline HS & 48 & 48 & 28 & $48(47)$ & $51(50)$ & $29(28)$ \\
\hline College & 20 & 36 & 64 & $14(14)$ & $31(33)$ & $65(66)$ \\
\hline Total & 100 & 100 & 100 & 100 & 100 & 100 \\
\hline
\end{tabular}

Notes: Parental education was measured in 1997. Weighted percentages are in parentheses. College $=$ college or more; HS = high school; No HS = no high school.

number of years needed, in principle, to reach the highest completed degree. This may penalize Danish data, as Danish data only include completed diplomas and degrees, whereas U.S. data include uncompleted education (as U.S. data capture grades completed). In addition, attrition in the U.S. data is higher for less educated families (Aughinbaugh and Gardecki 2007:5, note 7), which may lead to an overestimation of upward educational mobility in the United States relative to Denmark 
(we return to the issues of comparing educational attainment for the two countries in more detail in the data section). ${ }^{5}$

Nevertheless, we find educational mobility in Denmark to be higher than in the United States. This result holds regardless of whether we (1) use years of education or degrees attained or (2) measure educational origin by the father only or by the highest levels attained by both parents. In Denmark, more children of parents with less than 12 years of education (or no high school diploma) achieve 15 years of education or more (or a college degree) than in the United States. In Denmark, 20 percent of children of parents with no high school diploma achieve a college degree, whereas only 14 percent of U.S. children do so.

Using the relative risk measure, these differences translate into very different mobility patterns for the two countries. For example, when we focus on degrees attained and include information on the parents' highest education, the chance of obtaining a college degree or more for children with college-educated parents versus those with parents with no high school diploma is $(64 / 20)=3.2$ for Denmark and $(65 / 14)=4.6$ for the United States. The corresponding odds ratios of achieving a college degree or more versus having no high school diploma for children of parents with a college degree or more versus those with no high school diploma are $(64 / 8) /(20 / 32) \approx 13$ for Danish children and $(65 / 6) /(14 / 38) \approx 29$ for U.S. children. We will expand on these differences in our results section.

The discrepancies in reported mobility patterns between Denmark and the United States outlined here merit a meticulous investigation into the educational mobility patterns of the two countries. To arrive at a robust conclusion about the levels of educational mobility in the two countries, we proceed as follows. We begin by detailing the differences in the Danish and U.S. educational systems and assess the viability of comparing educational levels between the two countries. We thereafter perform a series of comparisons using well-known methodological approaches from economics and sociology.

\section{Danish and U.S. Educational Systems}

As the educational systems in Denmark and the United States differ in many ways, there are several difficulties in comparing levels of educational mobility in the two countries. For our cohorts, the educational system in Denmark is made up of nine years of compulsory education (first to ninth grades in primary and lower secondary school). Young people thereafter can choose between two separate tracks: a college-preparatory academic track, called "Gymnasium" (three years), or a track for vocational education and training (VET) (typically three to four years) to gain qualifications for a broad range of craft occupations (e.g., carpenters, electricians, construction, and service work). The Danish higher education system is made up of three educational institutions: (1) university institutions with a wide range of traditional liberal arts and professional programs offering three-year bachelor's degrees, two-year master's degrees, and three-year doctoral degrees (PhDs); (2) university colleges offering three- to four-year semiprofessional bachelor's programs (primarily educating teachers, nurses, and childcare and social workers); and (3) 
business academies offering a number of smaller two- to three-year programs for those seeking various jobs in the private sector.

The U.S. education system is more heterogenous than the Danish system, but most students enter the first grade in primary school at age 6 and continue into middle or junior high school when they reach the sixth or seventh grade. Nearly all students continue into high school (ninth or 10th to 12th grade), as children in the United States must be enrolled in school up to a certain age (see L \& H for a detailed explanation on p. 202-3). The U.S. educational system does not have separate tracks for academic and vocational educations. Instead, high school students may choose between vocational and academic courses. High school graduates then can enter college and graduate with an academic degree (ranging from one to four years). College graduates with bachelor's degrees (most often four years) can continue to pursue master's degrees (most often two years) and/or doctoral degrees (most often four years).

The cross-national differences in the educational systems mean that we must be careful when comparing levels and years of education. It is particularly difficult to compare the high school level, as Denmark has two completely separate tracks: vocational (VET) and college preparatory (Gymnasium). Whereas qualifications for working in skilled manual or service occupations in Denmark can only be obtained in vocational training and education programs at the high school level, vocational qualifications may be acquired in both high school and community colleges in the United States. For example, U.S. high schools and community colleges may offer auto repair and/or mechanic programs, whereas these qualifications can only be obtained at the VET level in Denmark. These differences are reflected in the United States' "college for all" approach, which aims to bring qualifications to all American students. In Denmark, as a significant number of students receive their qualifications through VET programs at the high school level, there is no "college for all" approach like in the United States.

At the bachelor's and master's levels, Danish graduates tend to have more years of schooling than U.S. graduates. Of the vast majority of Danish undergraduates (bachelor's-degree holders), more than 80 percent continue on to master's studies immediately after they have been awarded their bachelor's degrees. In Denmark, the formal division between bachelor's and master's degrees is a relatively recent one (an outcome of the European Bologna process), and in contrast to the United States, where most college students leave the education system with bachelor's degrees, there is no real job market for bachelor's degree holders in Denmark.

The differences in the educational systems mean that it is difficult to translate years of education into educational categories. For example, whereas 12 years of education is likely to equal a high school diploma in the United States, in Denmark, it will in nearly all cases cover a certificate from a VET program (as only a very small percentage end up with a college-preparatory academic diploma from Gymnasium only). Consequently, some Danish children will be categorized as less educated than their U.S. counterparts with similar qualifications-for example, when an auto mechanic has 12 years of education in Denmark (compulsory education and vocational school) but may have 14 years of education in the United States (compulsory education, high school, and community college). At the bachelor's and 
master's levels, however, university graduates in Denmark will be more highly educated than their U.S. counterparts even though they qualify for the same jobs. For example, civil servant positions in Denmark are typically occupied by graduates with master's degrees, whereas the same job positions in the United States are more likely to be occupied by graduates with bachelor's degrees.

\section{Data and Methods}

Our analyses are based on the same data sources used by L \& H: Danish administrative data and the National Longitudinal Survey of Youth 1997 (NLSY97). Table 3 shows detailed information on the data sources and variables used in this article. ${ }^{6}$ We use information on the educational attainments of the 1980-1984 cohorts of children in 2013 (when they were 29 to 33 years old), and we measure parental education in 1997 (when the children were between 13 and 17 years old).

As touched on earlier, an important difference in the data coding between Danish and U.S. data is that years of education are measured differently (i.e., grades completed in the U.S. data and degrees completed in the Danish data). As years of education that do not lead to a diploma or degree are disregarded in the Danish data, years of education in Denmark are likely to be underreported relative to the United States. ${ }^{7}$

As different analytical approaches may produce different conclusions (Torche 2016), we analyze the data using three major approaches to researching educational mobility: (1) a gradational approach measuring educational attainment by years of education, predominantly through linear regression models (Hertz et al. 2008); (2) a categorical approach measuring educational attainment by educational degree, predominantly using the odds ratio derived from logistical regression models (Breen and Jonsson 2000; Arum, Gamoran, and Shavit 2007; Jackson et al. 2008); and (3) a positional approach, similar to rank-rank regressions, measuring the education attained by how it ranks in the educational distribution (e.g., by using quartiles or deciles [Shavit and Park 2016]). The three approaches translate into three different measures.

\section{Continuous Measures}

We code education as the number of years of education associated with the highest degree attained by the individual. Like Hertz et al. (2008), we run regressions of children's schooling on parents' schooling, with no other covariates, and report two types of intergenerational associations between children and their parents' education: the intergenerational correlation $\left(r_{S}^{C}\right)$ and the beta coefficients of this association $\left(\beta_{S}^{C}\right)$. The link between the two measures is given as $r_{S}^{C}=\beta_{S}^{C}\left(\frac{\sigma_{0}^{C}}{\sigma_{1}^{C}}\right)$, in which $\sigma_{0}^{C}$ and $\sigma_{1}^{C}$ are the standard deviations of education for the parents and children. To measure family background, we use the fathers' highest grade and the parents' highest grade achieved. 
Table 3: Sample data and variables.

\begin{tabular}{ll}
\hline Denmark: All individuals born between 1980-1984 & $N$ \\
29- to 33-year-olds in 2013 & 256,986 \\
Years of education & 254,989 \\
Diplomas / degrees completed & 254,991 \\
Child's degree by father's degree & 235,757 \\
Child's degree by parents' degree 2013 & 250,954 \\
\hline United States: NLSY97 panel data for children born between 1980-1984 & $N$ \\
Total NLSY97 sample & 8,984 \\
Representative sample of 29- to 33-year-olds in 2013 & 6,748 \\
Educational information given in last round (2013): grades completed (degrees completed) & $5,226(5,269)$ \\
Educational information ever given: grades (degrees) & $6,670(6,727)$ \\
Child's degree (information from 2013) by father's degree (information ever given) & $2,755(3,473)$ \\
Child's degree (information from 2013) by parents' degree (information ever given) & $4,474(5,580)$ \\
\hline
\end{tabular}

Notes: Primary variables used in Danish data: children's and parents' highest degree (HFAUDD) and children's and parents' years of education (HFPRIA). Primary variables used in U.S. data: children's (CVC_HIGHEST_DEGREE_EVER_XRND; CVC_HIGHEST_DEGREE_EVER_EDT_2013) and parents' (coded from HHI_DEGREE) highest degree and children's (CVC_HGC_EVER_XRND; CV_HGC_EVER_EDT_2013) and parents' (CV_HGC_BIO_DAD_1997; CV_HGC_BIO_MOM_1997) years of education (highest grade completed). The U.S. sample includes optional weights to control for oversampling of black and Hispanic participants. NLSY97 = National Longitudinal Survey of Youth 1997.

\section{Categorical Measures}

We draw on information on the highest level of education that the individual has achieved, both in terms of years of education and highest degrees attained. Following the sociological literature on educational mobility, we rely on odds ratios in reporting the intergenerational associations between children's and parents' education (Hout 1983; Breen and Jonsson 2000).

\section{Positional Measures}

Inspired by income mobility studies introducing income deciles to study intergenerational income persistence (Mazumder 2005), a range of new studies has begun to analyze intergenerational educational persistence using a similar approach (Bol 2015; Thomsen 2015; Shavit and Park 2016). By comparing the likelihood of a child from one position in the educational distribution reaching a higher position in that distribution (e.g., moving from the least educated fifth to the most educated fifth), we circumvent many of the usual caveats of comparing educational mobility between countries and over time. ${ }^{8}$ As we are strictly interested in educational mobility in itself, we have ranked education for children and parents in the following way. We use years of education (the least "lumpy" educational variable) for Denmark and the United States. We split children's years of education into quintiles, which leave us with comparable groups for the two countries in the top fifth but not in the bottom fifth. Because of the uneven distribution of education at the lower end, 
we recode the quintiles into comparable group sizes so that we have four similar child groups in Denmark and the United States (the least educated 40 percent, the lower-middle 20 percent, the upper-middle 20 percent, and the top 20 percent). As we can use information on both parents (Thomsen 2015), the parental variable is less lumpy. ${ }^{9}$ We recode the parent groups to have similar sizes as the child groups (bottom 40 percent, lower-middle 20 percent, upper-middle 20 percent, and top 20 percent). We use odds ratios to report the positional associations between children's and parents' educational ranks.

\section{Results}

\section{Gradational Approach to Educational Mobility}

Table 4 shows the correlations and beta coefficients for the two countries. For the U.S. data, we show results both with the official survey weight and without. We calculate the parent-child correlations to be 0.39 in Denmark and 0.47 in the United States. The beta coefficients display a similar picture; Danish children are less affected by their family origins than are U.S. children-the Danish parent-to-child coefficient is 0.42 , whereas the U.S. coefficient is 0.46 .

Although these estimates show that Danish children are significantly more educationally mobile than their U.S. counterparts, we should exercise great caution when drawing conclusions based on linear analyses, especially when data are coded very differently in the two countries. First, as noted earlier, estimates will be volatile because of coding differences, and second, as we touched on earlier, the assumption that the parent-child relation is linear and monotonic is difficult to defend-particularly for countries with lumpy educational distributions (Blanden 2013). Third, correlations and ordinary least squares regression provide overall and uniform measures that do not differentiate between heterogeneous associations within the joint distribution of parents and children. In the next section, we present patterns of educational mobility using categorical measures. These measures overcome several of the obstacles listed above, as we can use variables for the two countries coded in more comparable ways and account for the nonlinear nature of education attained by parents and children.

\section{Categorical Approach to Educational Mobility}

A valuable feature of the categorical approach is not only that it recognizes the qualitative differences between different educational levels but also that the odds ratio measures, when used descriptively, have margin-insensitive properties (Breen and Jonsson 2000; Arum et al. 2007; Jackson et al. 2008). We code years of education and degrees attained by children and parents into three categories, as laid out in the previous section: (1) no education beyond compulsory school (0-11.99 years of schooling), (2) no education beyond high school (12-14.99 years of schooling), and (3) a college degree (15 years or more of schooling). Table 5 presents the odds ratios of achieving a high school diploma and college degree relative to no high school using information on degrees attained for coding children's and parents' 
Table 4: Educational mobility by continuous measures. Children's years of education (2013) by parents' years of education, coded from the highest degree attained. Correlations and beta coefficients for the 1980-1984 cohorts, with separate models for each country.

\begin{tabular}{|c|c|c|}
\hline & $\begin{array}{c}(1) \\
\text { Denmark } \\
(N \text { fathers }=235,757 ; N \text { parents }=250,954)\end{array}$ & $\begin{array}{c}(2) \\
\text { United States } \\
(N \text { fathers }=2,755 ; N \text { parents }=4,474)\end{array}$ \\
\hline & \multicolumn{2}{|c|}{ Correlations } \\
\hline Father-child & $\begin{array}{c}0.35^{*} \\
(0.00) \\
{[0.35 ; 0.35]}\end{array}$ & $\begin{array}{c}0.43^{*} \\
(0.02) \\
{[0.44 ; 0.46]}\end{array}$ \\
\hline Parents-child & $\begin{array}{l}0.39^{*} \\
(0.00) \\
{[0.39 ; 0.39]}\end{array}$ & $\begin{array}{c}0.47^{*} \\
(0.01) \\
{[0.44 ; 0.49]}\end{array}$ \\
\hline Father-child & $\begin{array}{c}0.37^{*} \\
(0.00) \\
{[0.37 ; 0.37]}\end{array}$ & $\begin{array}{c}0.40^{*} \\
(0.02) \\
{[0.37 ; 0.43]}\end{array}$ \\
\hline Parents-child & $\begin{array}{c}0.42^{*} \\
(0.00) \\
{[0.42 ; 0.42]}\end{array}$ & $\begin{array}{c}0.46^{*} \\
(0.01) \\
{[0.44 ; 0.49]}\end{array}$ \\
\hline
\end{tabular}

Notes: Weighted U.S. data. Standard errors are in parentheses, and $95 \%$ confidence intervals are in brackets. We tested the correlations (under the assumption of independent samples) and used T-test statistics for the regression coefficients to determine significant differences between the two countries (single-sided hypotheses, Denmark $<$ United States). All tests show that country differences are significant $(p<0.000)$. See online supplement Table $4 \mathrm{~A}$ for all estimates. ${ }^{*} p<0.01$.

educational attainment. We view information on degrees attained as superior to years of education, as degrees attained measures education in a more similar way for both countries (see online supplement Tables B1-B9 for more ways of coding educational attainment).

Table 5 shows that the odds ratio of achieving a college degree relative to getting no education beyond compulsory school for children of college-educated parents relative to parents with only compulsory education is twice as low in Denmark as in the United States. Danish children have an odds ratio of 13.2, whereas U.S. children have an odds ratio of 27.5. Similar differences are found if we use years of education instead of degrees attained, if we use fathers' education only, if we include or exclude weights, if we use information on the highest degree attained or enrolled in, or if we single out bachelor's and master's degrees (see online supplement Tables B4, B5, B6, and B7). ${ }^{10}$ In short, all logit models confirm that educational mobility in Denmark is higher than in the United States. ${ }^{11}$ In addition, we have run linear probability models of obtaining a college degree or not (online supplement Table 
Table 5: Educational mobility by categorical measures. Children's highest degree (2013) by parents' highest degree, coded from degrees attained. Odds ratios (reference: no high school), with separate multinomial logit models for each country.

(1)

Denmark $(N=250,954) \quad$ United States $(N=4,474)$

Parents' education:

High school completion

High school

College

Parents' education:

High school

College
$2.06^{*}$

[2.00; 2.11]

$2.40^{*}$

$[2.32 ; 2.48]$
$2.47^{*}$

$3.76^{*}$

$[3.76 ; 3.76]$

College completion

$3.64^{*}$

[3.52; 3.75]

$13.24^{*}$

(0.25)

[12.77; 13.73]
$5.30^{*}$

29.53*

(0.01)

[29.51; 29.54]

Notes: Weighted U.S. data. Standard errors are in parentheses, and $95 \%$ confidence intervals are in brackets. See online supplement Table 5A for all estimates (including marginal effects). ${ }^{*} p<0.01$.

B1), and these models corroborate the patterns found: children of parents with no high school diploma have a higher chance of obtaining a college degree in Denmark than in the United States (20 percent vs. 14 percent, respectively).

\section{Positional Approach to Educational Mobility}

Although categorical measures of education have many attractive properties over linear measures, they still present us with comparability problems (e.g., qualitative differences between nominally identical degrees in the two countries, as well as difficulties in comparing degrees intergenerationally). The positional approach enables us to address many of the problems inherent in the categorical measures. For example, the positional approach allows us to gauge how difficult it is for children with parents in the least educated fifth to reach the most educated fifth in each country.

We approach educational mobility as positional by comparing the odds ratios of achieving the top 20 percent relative to the lowest 40 percent in the educational distribution. As detailed in the data section, we have recoded years of education 
into quintiles and collapsed the two lower groups to get the same size groups for both children and parents in Denmark and the United States (i.e., the least educated 40 percent, the lower-middle 20 percent, the upper-middle 20 percent, and the top 20 percent). Table 6 shows that even when we apply a positional measure, the odds ratio for being in the top 20 percent relative to the lowest 40 percent is higher for U.S. children than for Danish children; the odds ratios come out to 8.8 for Denmark versus 20.5 for the United States (see also online supplement Table B9).

In sum, when we apply basic variables to compare educational mobility descriptively in the two countries, the tables presented here and in the online supplement show that educational mobility is consistently higher in Denmark than in the United States.

\section{Discussion and Conclusion}

Although a wide range of studies have found intergenerational educational mobility to be greater in Scandinavia than in countries such as the United Kingdom and the United States (Bjørklund et al. 2002; Esping-Andersen 2005; Jäntti et al. 2006; Hertz et al. 2008; Blanden 2013; Corak 2013), a recent article by Landersø and Heckman (2017) has argued that educational mobility in Denmark and the United States is remarkably similar. In the present study, we have reanalyzed educational mobility in Denmark and the United States using the same data sources, and we have arrived at the opposite conclusion. Educational mobility in Denmark and the United States is not similar; mobility in Denmark is significantly higher than in the United States. We find their statement to be empirically unsubstantiated and, consequently, not suitable for making policy recommendations.

L \& H base their statement on three sources (Landersø and Heckman 2017:19899): (1) OECD data, (2) a comparative analysis by Hertz et al. (2008), and (3) the authors' own tables on educational transitions for parents and children in Denmark and the United States. (1) L \& H use OECD (2014) data showing few cross-national differences in the social origin distribution of students in tertiary education. We have argued that the OECD figures reproduced by L \& H only showing the origin distribution within tertiary education cannot be used to draw conclusions about educational mobility. The relative risk measure provided by the OECD—which accounts for the distribution of education within each social group-shows that educational mobility is substantially higher in Denmark than in the United States (see Table A4.1a on page 92 and Table A4.1b on page 93 in OECD [2014]). (2) In addition to the OECD figures, $\mathrm{L} \& \mathrm{H}$ base their statement on a comparative study by Hertz et al. (2008), who use linear regression models to estimate the importance of family background on educational attainment for citizens ages 20 to 69 from 42 nations across 50 years. Hertz et al. (2008) do, in fact, find rather similar beta coefficient sizes for the United States and Denmark, but they find parent-to-child correlations-Hertz et al.'s preferred measure-to be higher in the United States than in Denmark. Whereas L \& H report only beta coefficients, we argue that both measures should be reported and that Hertz et al. (2008) show mixed results when the correlations are included. 
Table 6: Educational mobility by positional measures. Children's education (2013) by parents' education, coded from years of education. Odds ratios (reference: lowest 40 percent) for the 1980-1984 cohorts, with separate multinomial logit models for each country.

\begin{tabular}{|c|c|c|}
\hline & $\begin{array}{c}(1) \\
\text { Denmark }(N=250,954)\end{array}$ & $\begin{array}{c}(2) \\
\text { United States }(N=4,983)\end{array}$ \\
\hline & \multicolumn{2}{|c|}{ Lower middle (40-60 percent) } \\
\hline Lower middle (40-60 percent) & $\begin{array}{c}1.34^{*} \\
(0.02) \\
{[1.38 ; 1.38]}\end{array}$ & $\begin{array}{c}1.32^{*} \\
(0.00) \\
{[1.32 ; 1.32]}\end{array}$ \\
\hline Upper middle (60-80 percent) & $\begin{array}{c}1.26^{*} \\
(0.02) \\
{[1.22 ; 1.30]}\end{array}$ & $\begin{array}{c}2.25^{*} \\
(0.00) \\
{[2.25 ; 2.25]}\end{array}$ \\
\hline Top 20 percent (80-100 percent) & $\begin{array}{c}1.28^{*} \\
(0.02) \\
{[1.23 ; 1.32]}\end{array}$ & $\begin{array}{c}3.46^{*} \\
(0.00) \\
{[3.45 ; 3.46]}\end{array}$ \\
\hline & \multicolumn{2}{|c|}{ Upper middle (60-80 percent) } \\
\hline Lower middle (40-60 percent) & $\begin{array}{c}1.33^{*} \\
(0.02) \\
{[1.26 ; 1.37]}\end{array}$ & $\begin{array}{c}1.87^{*} \\
(0.00) \\
{[1.87 ; 1.88]}\end{array}$ \\
\hline Upper middle (60-80 percent) & $\begin{array}{c}1.69^{*} \\
(0.03) \\
{[1.64 ; 1.74]}\end{array}$ & $\begin{array}{c}4.66^{*} \\
(0.00) \\
{[4.66 ; 4.66]}\end{array}$ \\
\hline Top 20 percent (80-100 percent) & $\begin{array}{c}3.40^{*} \\
(0.05) \\
{[3.29 ; 3.50]}\end{array}$ & $\begin{array}{c}12.88^{*} \\
(0.00) \\
{[12.87 ; 12.88]}\end{array}$ \\
\hline & \multicolumn{2}{|c|}{ Top 20 percent (80-100 percent) } \\
\hline Lower middle (40-60 percent) & $\begin{array}{c}1.30^{*} \\
(0.02) \\
{[1.26 ; 1.34]}\end{array}$ & $\begin{array}{c}2.42^{*} \\
(0.00) \\
{[2.42 ; 2.43]}\end{array}$ \\
\hline Upper middle (60-80 percent) & $\begin{array}{c}2.35^{*} \\
(0.04) \\
{[2.27 ; 2.43]}\end{array}$ & $\begin{array}{c}5.56^{*} \\
(0.00) \\
{[5.56 ; 5.57]}\end{array}$ \\
\hline Top 20 percent (80-100 percent) & $\begin{array}{c}8.84^{*} \\
(0.14) \\
{[8.58 ; 9.11]}\end{array}$ & $\begin{array}{c}20.09^{*} \\
(0.00) \\
{[20.09 ; 20.10]}\end{array}$ \\
\hline
\end{tabular}

Notes: Weighted U.S. data. Standard errors are in parentheses, and $95 \%$ confidence intervals are in brackets. See online supplement Table 6A for all estimates (including marginal effects). ${ }^{*} p<0.01$. 
(3) L \& H also base their statement on their own depictions of the intergenerational association between fathers' and their children's education (Figure A30). We have reanalyzed these patterns for the latest cohorts of 29- to 33-year-olds in 2013 in both countries. Looking at raw transition tables, we find that children of parents with less than 12 years of education are more likely to achieve 15 years of education (or more) in Denmark than in the United States. We also have modeled the transitions using gradational, categorical, and positional approaches. The gradational approach views children's education as a linear and monotonic function of their parents' education. We found the parent-to-child correlations and regression estimates to be significantly lower for Danish children than for U.S. children. ${ }^{12}$ The categorical approach allows us to use more comparable data (degrees attained) and to recognize qualitative differences between different educational levels. Using various categorical measures, we consistently find educational mobility to be higher in Denmark than in the United States, and this result corresponds with other studies on social and educational mobility finding higher upward mobility in Scandinavian countries than in the United States (e.g., Breen et al. 2010; Blanden 2013; Eurofound 2017). In the positional approach, we compare the likelihoods of children from different origin positions in the educational distribution reaching other positions in that distribution. This approach is particularly valuable in comparative analysis over time and between countries, where nominally similar educational categories can be qualitatively different and have different effects on outcomes (for similar remarks, see Di Stasio, Bol, and van de Werfhorst [2016]). Again, we find educational mobility to be higher in Denmark than in the United States.

As we cannot find a lack of educational mobility in Denmark compared with the United States, we dispute the conclusion by L \& H that wage compression and high levels of welfare benefits are counterproductive in providing incentives for pursuing education (Landersø and Heckman 2017:220). On the contrary, the relatively high educational mobility in Denmark could, for the sake of argument, be the result of a welfare state providing sufficient incentives for pursuing education. A welfare regime in which the choice of higher education is associated with low social and economic risks may support mobility, whereas a high-risk, limited welfare regime, such as the one in the United States, may hamper mobility (for similar arguments, see Esping-Andersen [2004]). Because our article relies on descriptive methods only, this reasoning obviously will remain speculative, but we want to illustrate an important point: different estimates of mobility patterns can lead to different hypotheses about the workings of welfare regimes and, ultimately, to different policy recommendations. We have made a case at the descriptive level for educational mobility being higher in Denmark than in the United States, thereby questioning the statement made by L \& $\mathrm{H}$. The "cautionary note to the many enthusiasts endorsing the Scandinavian welfare state" sent by L \& H (p. 220) should, in our view, rather be a cautionary note about arriving too hastily at conclusions about educational mobility patterns-especially if these conclusions serve as stepping stones for advancing welfare-state policy recommendations. 


\section{Notes}

1 Even though L \& H (2017) only use a small part of their article to discuss educational mobility in Denmark and the United States (p. 196-99), we focus specifically on this part because this is where they establish that educational mobility in Denmark and the United States is similar, and they use this finding as a point of departure for the remainder of their article.

2 The OECD (2014) does not provide the figures used for calculating its odds ratios, but an example can easily be constructed showing how similar destination row percentages may cover up very different mobility patterns. Consider the following hypothetical mobility tables for countries A and B. Both countries have row percentage distributions for children in tertiary education resembling those reported in Figure 6 in $\mathrm{L} \& \mathrm{H}$, but they have very different mobility patterns. In country A, 10 percent of all children of parents with no upper secondary education progress to tertiary education, whereas in country B, 20 percent do so. In short, origin distributions (column percentages) are needed to properly assess educational mobility patterns.

\begin{tabular}{|c|c|c|c|c|c|c|c|}
\hline & & \multicolumn{3}{|c|}{ Country A $(N=396)$} & \multicolumn{3}{|c|}{ Country B $(N=635)$} \\
\hline & & \multicolumn{3}{|c|}{ Parents } & \multicolumn{3}{|c|}{ Parents } \\
\hline & & $\begin{array}{l}\text { Below } \\
\text { upper } \\
\text { secondary }\end{array}$ & $\begin{array}{l}\text { Upper } \\
\text { secondary }\end{array}$ & $\begin{array}{l}\text { Tertiary } \\
\text { education }\end{array}$ & $\begin{array}{l}\text { Below } \\
\text { upper } \\
\text { secondary }\end{array}$ & $\begin{array}{l}\text { Upper } \\
\text { secondary }\end{array}$ & $\begin{array}{l}\text { Tertiary } \\
\text { education }\end{array}$ \\
\hline \multirow{3}{*}{ Children } & $\begin{array}{l}\text { Upper } \\
\text { secondary } \\
\text { education }\end{array}$ & $50(50 \%)$ & 40 & 20 & $40(40 \%)$ & 60 & 40 \\
\hline & $\begin{array}{l}\text { Below } \\
\text { upper } \\
\text { secondary } \\
\text { education }\end{array}$ & $40(40 \%)$ & 64 & 57 & $40(40 \%)$ & 50 & 120 \\
\hline & $\begin{array}{l}\text { Tertiary } \\
\text { education }\end{array}$ & $\begin{array}{l}10(10 \%) \\
{[8 \%]}\end{array}$ & $\begin{array}{l}42 \\
{[34 \%]}\end{array}$ & $\begin{array}{l}73 \\
{[58 \%]}\end{array}$ & $\begin{array}{l}20(20 \%) \\
{[7 \%]}\end{array}$ & $\begin{array}{l}85 \\
{[30 \%]}\end{array}$ & $\begin{array}{l}180 \\
{[63 \%]}\end{array}$ \\
\hline
\end{tabular}

Notes: Column percentages are in parentheses; row percentages are in brackets.

3 We thank Rasmus Landersø for generously providing us with Stata do-files. Our own do-files can be obtained from the authors upon request.

4 In their Online Appendix Figure A30, it appears that L \& H use a lower cutoff for years of education needed to end up in the college group for the United States (14 years) than for Denmark (15 years). We use the same cutoffs for Denmark and the United States but include L \& H's cutoff in later online supplement models (Table B2).

5 The U.S. data have weights, but these are only designed to account for the oversampling of black and Hispanic participants.

6 Replication do-files are available upon request. Data from the National Longitudinal Survey of Youth is publicly available (Bureau of Labor Statistics 2015). For information on how to gain access to the Danish administrative data, please visit the following link: https://www.dst.dk/en/TilSalg/Forskningsservice.

7 Whereas Danish administrative data record the highest education ever attained each year, the NLSY97 provides information on either the highest grade or degree reported in the last round (round 16 in 2013) or the highest degree ever reported. This means that the researcher will have to make a tradeoff between larger Ns with information from the latest and previous rounds (i.e., potentially incomplete information about individuals' educational attainment) versus smaller Ns with information from the 2013 round only. 
We include both measures in our models (see the online supplement). In addition, whereas the educational level of parents is automatically linked to the children in Danish administrative data, the information on parental education in the U.S. data is given either as (1) the grade attained by the mother and father (with information given by the mother in the round) or (2) the degrees attained by the mother and father (with information provided by the child in the 1997 round). Scholars have found that children's accounts of their parents' education lead to underestimation of socioeconomic disparities (Engzell and Jonsson 2015). We apply both measures in our analyses.

8 Educational categories may be on the same level formally while covering very different education forms (e.g., the difference between attending "high school" in Denmark and in the United States). In addition, educational categories may formally be the same as 30 or 40 years ago, but occupational prospects may have changed dramatically (because of educational expansion, labor market demands, etc.). Measuring education in relative terms accounts for many (but certainly not all) of these caveats. One way to code education as a positional good is to divide education into quartiles or quintiles (if the lumpiness of education can be addressed properly). Another way is to use returns to education, occupational prestige, or other labor market outcomes to rank education levels.

9 We code information in the following way. The most educated parent is the primary source of information, and the other biological parent provides additional information. For example, say that the mother has 16 years of education and the father has 14 years; we recode this information into a notation of 16.14, retaining information on both parents' years of education. This provides us with a highly gradational measure of the level of education among parents. If information on one parent is missing (e.g., if there is only information on the mother) the father's figure is set at 16.00 .

10 For example, Table B8 in the online supplement shows that the odds ratio for obtaining an master's degree for children of college-educated parents compared with those whose parents have only compulsory education is 30 for Denmark and 52 for the United States.

11 As some similar occupations require skills at different levels in Denmark and the United States (as described in the section on the Danish and U.S. educational systems), we also have run models separating shorter college degrees (merging high school together with business academies for Denmark and associate colleges in the United States) from longer college degrees (see online supplement Table B6). Once again, we find major differences in educational mobility between the two countries in favor of Denmark; the odds ratios of achieving shorter college degrees are 14.9 for Denmark and 32.8 for the United States.

12 We arrive at somewhat different results than Hertz et al. (2008), mainly for two reasons: (1) We code years of education as the number of years associated with the highest degree attained, whereas Hertz et al. use information on grades completed. (2) Hertz et al. average a heterogeneous sample of about 2,700 Danish children born between 1933 and 1978 , whereas our analysis is performed on more homogenous cohort data of children born between 1980 and 1984 .

\section{References}

Arum, Richard, Adam Gamoran, and Yossi Shavit. 2007. "More Inclusion Than Diversion: Expansion, Differentiation and Market Structure in Higher Education." Pp. 1-35 in Stratification in Higher Education: A Comparative Study, edited by Shavit, Y., R. Arum, and A. Gamoran. California: Stanford University Press. 
Aughinbaugh, Alison, and Rosella M. Gardecki. 2007. Attrition in the National Longitudinal Survey of Youth 1997. Washington, DC: Bureau of Labour Statistics.

Baumann, Andreas. 2017. “Den urokkelig ulighed i uddannelse [Persistent inequality in education]." Mandag Morgen, October 9. Retrieved November 29, 2017. https: //www.mm.dk/artikel/den-urokkelige-ulighed-i-uddannelse.

Beller, Emily. 2009. "Bringing Intergenerational Social Mobility Research into the TwentyFirst Century: Why Mothers Matter." American Sociological Review 74(4):507-28. https : //doi.org/10.1177/000312240907400401.

Bjørklund, Anders, Tor Eriksson, Markus Jäntti, Oddbjörn Raaum, and Eva Österbacka. 2002. "Brother Correlations in Earnings in Denmark, Finland, Norway and Sweden Compared to the United States." Journal of Population Economics 15(4):757-72. https : //doi.org/10.1007/s001480100095.

Black, Sandra E., and Paul J. Devereux. 2011. "Recent Developments in Intergenerational Mobility." Pp. 1487-541 in Handbook of Labour Economics, Vol. 4, edited by O. Ashenfelter and D. Card. Amsterdam: Elsevier. https ://doi.org/10.1016/S0169-7218(11)02414-2.

Blanden, Jo. 2013. “Cross-Country Rankings in Intergenerational Mobility: A Comparison of Approaches from Economics and Sociology." Journal of Economic Surveys 27(1):38-73. https://doi.org/10.1111/j.1467-6419.2011.00690.x.

Bol, Thijs. 2015. "Has Education Become More Positional? Educational Expansion and Labour Market Outcomes, 1985-2007." Acta Sociologica 58(2):105-20. https : //doi .org/ 10.1177/0001699315570918.

Breen, Richard, and Jan O. Jonsson. 2000. "Analyzing Educational Careers: A Multinomial Transition Model." American Sociological Review 65(5):754-72. https://doi.org/10. $2307 / 2657545$.

Breen, Richard, and Jan O. Jonsson. 2005. "Inequality of Opportunity in Comparative Perspective: Recent Research on Educational Attainment and Social Mobility." Annual Review of Sociology 31:223-243. https://doi .org/10.1146/annurev . soc. 31.041304.122232.

Breen, Richard, Ruud Luijkx, Walter Müller, and Reinhard Pollak. 2010. "Long-term Trends in Educational Inequality in Europe: Class Inequalities and Gender Differences." European Sociological Review 26(1):31-48. https : //doi .org/10.1093/esr/jcp001.

Corak, Miles. 2013. "Income Inequality, Equality of Opportunity, and Intergenerational Mobility." Journal of Economic Perspectives 27(3):79-102. https ://doi .org/10.1257/jep. 27.3.79.

Di Stasio, Valentina, Thijs Bol, and Herman G. van de Werfhorst. 2016. "What Makes Education Positional? Institutions, Overeducation and the Competition for Jobs." Research in Social Stratification and Mobility 43:53-63. https://doi.org/10.1016/j.rssm. 2015. 09.005.

Engzell, Per, and Jan O. Jonsson. 2015. “Estimating Social and Ethnic Inequality in School Surveys: Biases from Child Misreporting and Parent Nonresponse." European Sociological Review 31(3):312-25. https://doi .org/10.1093/esr/jcv005.

Esping-Andersen, Gosta. 2004. "Untying the Gordian Knot of Social Inheritance." Research in Social Stratification and Mobility 21(1):115-38. https://doi.org/10.1016/ S0276-5624(04) 21007-1.

Esping-Andersen, Gosta. 2005. "Social Inheritance and Equal Opportunities Policies." Pp. 14-30 in Maintaining Momentum: Promoting Social Mobility and Life Chances from Early Years to Adulthood, edited by S. Delorenzi, P. Robinson, and J. Reed. London: The Institute for Public Policy Research. 
Eurofound. 2017. Social Mobility in the EU. Luxembourg: Publications Office of the European Union.

Hertz, Tom, Tamara Jayasundera, Patrizio Piraino, Sibel Selcuk, Nicole Smith, and Alina Verashchagina. 2008. "The Inheritance of Educational Inequality: International Comparisons and Fifty-Year Trends." The B.E. Journal of Economic Analysis and Policy 7(2):1-46. https://doi.org/10.2202/1935-1682.1775.

Hout, Michael. 1983. Mobility Tables. Newbury Park: Sage Publications. https://doi .org/ 10.4135/9781412985086.

Jackson, Michelle, Ruud Luijkx, Reinhard Pollak, Louis-André Vallet, Herman G. van de Werfhorst. 2008. "Educational Fields of Study and the Intergenerational Mobility Process in Comparative Perspective." International Journal of Comparative Sociology 49(4-5):369-88. https://doi.org/10.1177/0020715208093082.

Jäntti, Markus, Bernt Bratsberg, Knut Røed, Oddbjörn Raaum, Robin Naylor, Eva Österbacka, Anders Björklund, and Tor Eriksson. 2006. “American Exceptionalism in a New Light: A Comparison of Intergenerational Earnings Mobility in the Nordic Countries, the United Kingdom and the United States (Discussion Paper, No. 1938)." Bonn, Germany: Institute for the Study of Labour.

Landersø, Rasmus. 2016. “Lige muligheder er mere drøm end virkelighed i Danmark [Equality of opportunity is more dream than reality in Denmark]." Politiken, July 11. Retrieved November 29, 2017. https://politiken.dk/debat/kroniken/art5629376/ Lige-muligheder-er-mere- $\mathrm{dr} \% \mathrm{C} 3 \% \mathrm{~B} 8 \mathrm{~m}$-end-virkelighed-i-Danmark.

Landersø, Rasmus, and James J. Heckman. 2017. "The Scandinavian Fantasy: The Sources of Intergenerational Mobility in Denmark and the US." Scandinavian Journal of Economics 119(1):178-230. https://doi.org/10.1111/sjoe.12219.

Mazumder, Bhashkar. 2005. “The Apple Falls Even Closer to the Tree than We Thought: New and Revised Estimates of the Intergenerational Inheritance of Earnings." Pp. 80-99 in Unequal Chances: Family Background and Economic Success, edited by S. Bowles, H. Gintis, and M. Osborne Groves. New Jersey: Princeton University Press.

O'Brien, Matt. 2016. "This Country Has Figured Out the Only Way to Save the American Dream." Washington Post, August 3. Retrieved November 29, 2017. https://www.washingtonpost.com/news/wonk/wp/2016/08/03/ theres-only-one-way-to-save-the-american-dream/?utm_term=.d69abcb3e445.

Organisation for Economic Cooperation and Development. 2014. Education at a Glance 2014: OECD Indicators. Paris: OECD Publishing.

Organisation for Economic Cooperation and Development. 2017. Educational Opportunity for All: Overcoming Inequality throughout the Life Course. Paris: OECD Publishing.

Shavit, Yossi, and Hyunjoon Park. 2016. "Introduction to the Special Issue: Education as a Positional Good." Research in Social Stratification and Mobility 43:1-3. https : //doi .org/ 10.1016/j.rssm.2016.03.003.

Thompson, Derek. 2016. "Denmark Isn't Magic." The Atlantic, August 2. Retrieved November 29, 2017. https://www.theatlantic.com/business/archive/2016/08/ the-american-dream-isnt-alive-in-denmark/494141/.

Thomsen, Jens-Peter. 2015. “Maintaining Inequality Effectively? Access to Higher Education Programmes in a Universalist Welfare State in Periods of Educational Expansion 1984-2010." European Sociological Review 31(6):683-96. https://doi .org/10.1093/esr/ jcv067.

Torche, Florencia. 2016. "Education and the Intergenerational Transmission of Advantage in the US." Pp. 237-54 in Education, Occupation and Social Origin: A Comparative Analysis 
of the Transmission of Socio-Economic Inequalities, edited by F. Bernardi, and G. Ballarino. Cheltenham: Edward Elgar Publishing. https://doi.org/10.4337/9781785360459. 00020 .

Bureau of Labor Statistics, U.S. Department of Labor. 2015. "National Longitudinal Survey of Youth, 1997 cohort." Produced by the National Opinion Research Center, the University of Chicago and distributed by the Center for Human Resource Research, The Ohio State University. Columbus, OH. Retrieved January 31, 2018. https://www.nlsinfo.org/ content/cohorts/nlsy97.

Stefan B. Andrade: Department of Social Policy and Welfare, The Danish Center for Social Science Research. E-mail: sba@vive.dk.

Jens-Peter Thomsen: Department of Social Policy and Welfare, The Danish Center for Social Science Research. E-mail: jpt@vive.dk. 